\title{
LAPAROSCOPIC CHOLECYSTECTOMY UNDER SPINAL ANAESTHESIA- A PROSPECTIVE, RANDOMIZED COMPARATIVE STUDY BETWEEN INTRATHECAL FENTANYL AND CLONIDINE AS ADJUVANT WITH 0.5\% HYPERBARIC BUPIVACAINE
}

\author{
Asim Kumar Maiti1, Debasish Bhar², Harsa Prava Dutta³, Soumi Banerjee ${ }^{4}$, Rita Pal5, Sudeshna Bhar Kundu ${ }^{6}$ \\ ${ }^{1}$ Assistant Professor, Department of Anaesthesiology, Midnapore Medical College, Medinipur, West Bengal, India. \\ ${ }^{2}$ Associate Professor, Department of Anaesthesiology, Midnapore Medical College, Medinipur, West Bengal, India. \\ 3Postgraduate Trainee, Department of Anaesthesiology, Midnapore Medical College, Medinipur, West Bengal, India. \\ ${ }_{4}^{4}$ Postgraduate Trainee, Department of Anaesthesiology, Midnapore Medical College, Medinipur, West Bengal, India. \\ ${ }_{5}^{5}$ Professor, Department of Anaesthesiology, Midnapore Medical College, Medinipur, West Bengal, India. \\ ${ }^{6}$ Associate Professor, Department of Anaesthesiology, Calcutta National Medical College, Kolkata, West Bengal, India.
}

\begin{tabular}{l}
\hline ABSTRACT \\
BACKGROUND \\
Laparoscopic cholecystectomy is usually done under general anaesthesia but in recent times, several studies have suggested that \\
laparoscopic surgeries are safely done under spinal anaesthesia. To improve the quality of spinal anaesthesia and post-operative \\
analgesia, clonidine and fentanyl have been added with hyperbaric bupivacaine.
\end{tabular}

\section{MATERIALS AND METHODS}

After obtaining permission from institutional ethical committee, a prospective, randomised study was conducted at a tertiary level hospital (Medical College) for a period of 3 years. Initially 300 patients were included in the study and they were randomly divided into three groups each comprising of 100 patients. In Group A patients, general anaesthesia was administered, group B received spinal anaesthesia with $3.5 \mathrm{ml}$ of $0.5 \%$ hyperbaric bupivacaine with fentanyl $25 \mathrm{mcg}$ and patients belonging to group $\mathrm{C}$ received spinal anaesthesia with $3.5 \mathrm{ml}$ of $0.5 \%$ hyperbaric bupivacaine with $30 \mathrm{mcg}$ of clonidine. Intra operative hypotension, bradycardia, shoulder tip pain and abdominal discomfort/pain were recorded. Post-operative vitals, analgesia and complications were also compared among the groups.

\section{RESULTS}

Incidence of hypotension, bradycardia and abdominal discomfort was significantly higher in group C compared to group B $(\mathrm{p}<0.05)$. Abdominal pain started significantly earlier in group A patients compared to other groups. Post-operative pain was better controlled in group $\mathrm{C}$ compared to other groups.

\section{CONCLUSION}

Intrathecal fentanyl as adjuvant to bupivacaine is a better choice as it significantly reduces intra operative abdominal disc omfort. Though duration of post-operative analgesia is more with clonidine compared to fentanyl, it has higher incidence of hypotension and bradycardia.

\section{KEY WORDS}

Spinal Anaesthesia, Laparoscopic Cholecystectomy, Fentanyl, Clonidine.

HOW TO CITE THIS ARTICLE: Maiti AK, Bhar D, Dutta HP, et al. Laparoscopic cholecystectomy under spinal anaesthesia- a prospective, randomized comparative study between intrathecal fentanyl and clonidine as adjuvant with $0.5 \%$ hyperbaric bupivacaine. J. Evolution Med. Dent. Sci. 2018;7(51):5420-5425, DOI: 10.14260/jemds/2018/1200

\section{BACKGROUND}

It was believed that laparoscopic surgery required general anaesthesia (GA) with endotracheal intubation to prevent aspiration, abdominal discomfort and hypercarbia which were expected secondary to carbon dioxide $\left(\mathrm{CO}_{2}\right)$ pneumoperitoneum. [1] So, GA is the anaesthetic technique of choice for laparoscopic cholecystectomy (LC) from the very beginning. But recently several studies reported that $\mathrm{LC}$ with low-pressure $\mathrm{CO}_{2}$ pneumoperitoneum can be safely performed under spinal anaesthesia (SA).[2,3]

'Financial or Other Competing Interest': None.

Submission 07-11-2018, Peer Review 30-11-2018,

Acceptance 07-12-2018, Published 17-12-2018.

Corresponding Author:

Dr. Debasish Bhar,

Baalajee Ganges, Block D,

Flat No. 304, 105D, Bidhan Nagar Road,

Kolkata-700067, West Bengal, India.

E-mail: debasish_bhar@rediffmail.com

DOI: $10.14260 /$ jemds/2018/1200

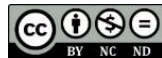

Studies and case series also have been published using spinal anaesthesia (SA), thoracic segmental spinal anaesthesia and epidural anaesthesia for LC.[4,5,6] All the studies compared between general and spinal anaesthesia using intrathecal $0.5 \%$ hyperbaric bupivacaine with or without fentanyl. But to the horizon of our knowledge no study till date has been published comparing fentanyl and clonidine as adjuvant to intrathecal $0.5 \%$ hyperbaric bupivacaine in LC. Thus, the aim of this study is to compare intraoperative and postoperative complications between three groups of healthy patients posted for LC under GA, spinal anaesthesia with $25 \mathrm{mcg}$ of intrathecal fentanyl and spinal anaesthesia with $30 \mathrm{mcg}$ of intrathecal clonidine.

\section{MATERIALS AND METHODS}

After obtaining permission from institutional ethical committee a prospective, randomised study was conducted at a tertiary level hospital (Medical College) for a period of 3 years from January 2014 to December 2016. Initially 300 patients were included in the study and they were randomly 
divided in three groups each comprising 100 patients. In Group A patients, general anaesthesia was administered, group B received spinal anaesthesia with $3.5 \mathrm{ml}$ of $0.5 \%$ hyperbaric bupivacaine with fentanyl $25 \mathrm{mcg}$ and patients belonging to group $C$ received spinal anaesthesia with $3.5 \mathrm{ml}$ of $0.5 \%$ hyperbaric bupivacaine with $30 \mathrm{mcg}$ of clonidine.

\section{Newly diagnosed cases of cholelithiasis posted for LC who met the following criteria were included in the study-}

1. American Society of Anaesthesiologist's (ASA) physical status I

2. Age between 18 and 65 years.

Patients with body mass index (BMI) above $30 \mathrm{~kg} / \mathrm{m}^{2}$, acute cholecystitis, pancreatitis or cholangitis, previous open surgery in the upper abdomen, suspected/confirmed common bile duct stones, anxiety prone patient, patients with diagnosed psychological morbidity and presence of contraindications for spinal anaesthesia were excluded from the study.

All the patients were interviewed by the anaesthesiologist in a pre-operative visit on the day before surgery who explained them about the possible intra operative events while under SA, like vomiting, shoulder pain, anxiety etc. and assured them that appropriate measure will be taken by administering intravenous (iv) medications or GA necessary. Patients were also explained about the study and after obtaining written informed consent they were included in the study.

Randomization was done by giving a sealed envelope selected by the patient containing a number belonging to any of the three groups. The numbers were distributed randomly to three groups by a computer-generated random number table.

Each patient received ranitidine $50 \mathrm{mg}$ intravenously (iv) and metoclopramide $10 \mathrm{mg}$ intramuscularly (im) one hour before operation. Pre-operative values of heart rate (HR), systolic blood pressure (SBP), diastolic blood pressure (DBP), respiratory rate $(\mathrm{RR})$ and oxygen saturation $\left(\mathrm{SpO}_{2}\right)$ were recorded in the operation theatre before giving any medication. Inj glycopyrrolate $0.2 \mathrm{mg}$ was administered intramuscularly (im) to all patient $10 \mathrm{~min}$ before operation.

In group A patients, general anaesthesia was induced with $2.5 \mathrm{mg} / \mathrm{kg}$ of propofol, $2 \mu \mathrm{g} / \mathrm{kg}$ of fentanyl and 0.1 $\mathrm{mg} / \mathrm{kg}$ of vecuronium iv. All patients were ventilated with $100 \%$ oxygen with a face mask, followed by laryngoscopy and tracheal intubation. After intubation the respiratory rate was adjusted to maintain end tidal carbon dioxide $\left(\mathrm{EtCO}_{2}\right)$ between 30 and $35 \mathrm{mmHg}$ with a tidal volume of $8 \mathrm{ml} / \mathrm{kg}$. Maintenance of anaesthesia was done with oxygen, nitrous oxide $\left(\mathrm{N}_{2} \mathrm{O}\right)$, isoflurane and vecuronium. Residual neuromuscular blockade was antagonized with neostigmine $(50 \mu \mathrm{g} / \mathrm{kg})$ and glycopyrrolate $(10 \mu \mathrm{g} / \mathrm{kg})$ at the end of the surgery.

For the patients belonging to group B and C subarachnoid block was performed under all aseptic and antiseptic precaution at L2-3 or 3-4 interspace with 26-gauge Quincke needle in lateral decubitus. After the position of the needle in the subarachnoid space was confirmed by backflow of cerebrospinal fluid (CSF), $0.5 \%$ hyperbaric bupivacaine $(3.5$ $\mathrm{ml}$ ) with fentanyl $25 \mathrm{mcg}$ was injected intrathecally in group
B patients and patients belonging to group C received $0.5 \%$ hyperbaric bupivacaine with clonidine $30 \mathrm{mcg}$ intrathecally. Then, the patients were placed in the supine position with a 10-degree head-down tilt.

To assess the level of sensory block a blunt pin was taken and placed over the clavicle of the patient and the sensation of pin prick at that region was taken as reference point and then the pin was pricked on the anterior abdominal wall at the level of umbilicus (T10) on both sides and compared with the reference point. Once the level of sensory block reached T6 (Xiphisternum) level, the surgical table was placed in the horizontal position and the surgery was allowed to start after giving $1 \mathrm{mg}$ of midazolam iv. All patients under spinal anaesthesia received moist $\mathrm{O}_{2} 4 \mathrm{~L} / \mathrm{min}$ via polymask.

Laparoscopic cholecystectomy was performed according to the standard four-port technique. After the second trocar, in all the patients of three groups the subdiaphragmatic surface of the liver was bathed with $30 \mathrm{ml}$ of a solution which contained $10 \mathrm{ml}$ of $2 \%$ lignocaine, $10 \mathrm{ml}$ of $0.5 \%$ bupivacaine and $10 \mathrm{ml}$ of normal saline. Pneumoperitoneum was induced with $\mathrm{CO} 2$ with intra-abdominal pressure (IAP) of $8 \mathrm{mmHg}$ in all patients. Reverse Trendelenburg and left lateral tilt of the patient was done after pneumoperitoneum was established and IAP was increased to $10 \mathrm{mmHg}$ if required.

Patients complaining of shoulder pain or abdominal discomfort even after administration of local anaesthetic mixture received $25 \mathrm{mg}$ of ketamine iv. If patient still complained of pain another $25 \mathrm{mg}$ of ketamine was administered. If pain was not relieved even after that GA was administered with endotracheal intubation and the patient was excluded from the study (Fig. 1).

\section{The following criteria were established for conversion of the anaesthesia from $S A$ to $G A$}

1. Patient anxiety

2. Shoulder pain which was not relieved by addition of ketamine

3. Operative difficulty due to adhesion, bleeding etc.

4. Patients in whom sensory block up to T6 level could not be achieved.

Nasogastric tube was introduced only if the surgeon desired decompression of stomach. After gall bladder had been extracted, the gall bladder fossa of liver was bathed with $20 \mathrm{ml}$ of solution containing $5 \mathrm{ml}$ of $2 \%$ lignocaine and $5 \mathrm{ml}$ of $0.5 \%$ bupivacaine dissolved in $10 \mathrm{ml}$ of normal saline in patients of all the three groups. All cases were performed by the same anaesthesiologist and surgical team.

In group A Ringer's lactate (RL) was transfused to administer maintenance fluid and correct the fluid deficit (depending on the hours of fasting). In group B and C RL was transfused @ $20 \mathrm{ml} / \mathrm{kg}$ for first $20 \mathrm{~min}$ then at $10 \mathrm{ml} / \mathrm{kg} / \mathrm{h}$ for rest of the intraoperative period.[7] Hypotension was defined as systolic blood pressure (SBP) $<90 \mathrm{mmHg}$ or $<70 \%$ of the baseline value and was treated with $300 \mathrm{ml}$ of additional fluid or, if not responsive within $5 \mathrm{~min}$, with mephentermine (6 mg) iv.[8]

Operative time, insufflations time and intra operative fluid intake were noted in all the groups. In group B and C any intraoperative adverse effects like nausea, vomiting, pruritus, shoulder pain and abdominal discomfort were recorded. 
Hemodynamic changes like bradycardia $(\mathrm{HR}<60)$, tachycardia (HR>100), hypertension (SBP >140 mmHg or DBP $>90 \mathrm{mmHg}$ ) and hypotension were recorded in all patients. Bradycardia (60 or less heart beat per min) was treated with iv atropine $(0.6 \mathrm{mg})$. Chlorpheniramine $10 \mathrm{mg}$ im was used for pruritus as required. Intraoperative nausea and vomiting in group $\mathrm{B}$ and $\mathrm{C}$ was treated by correction of blood pressure and ondansetron 4-8 $\mathrm{mg}$ iv as required.[9]

Requirement of ketamine, mephentermine and atropine in group B and C were recorded. Patient and surgeon satisfaction were recorded using a subjective verbal rating scale for satisfaction $(1 / 5$ very dissatisfied, $2 / 5$ dissatisfied, $3 / 5$ neutral, $4 / 5$ satisfied, and 5/5 very satisfied).[5]

ECG (Electrocardiogram), $\mathrm{HR}, \mathrm{RR}$ and $\mathrm{SpO}_{2}$ were monitored continuously in all patients intraoperatively. Non invasive blood pressure (NIBP) was measured at every $2 \mathrm{~min}$ interval for $20 \mathrm{~min}$ after induction of spinal anesthesia and at 5 min interval thereafter in group B and C. In group A NIBP was measured at 5 min interval from the beginning.

All patients were transferred to the post anaesthesia care unit (PACU). Discharge time was defined as the time from admission to PACU until the patient met all discharge criteria. These included mental alertness, stable vital signs, absence of nausea, control of pain, ability to ambulate, and (For regional techniques) voiding. Side effects measured were the incidence of hypertension, hypotension, bradycardia, tachycardia, nausea, vomiting, headache, urine retention, sore throat and pruritus during PACU stay.

The severity of postoperative pain was assessed by using a $10 \mathrm{~cm}$ visual analogue scale (VAS) (0 - no pain, 10 - worst possible pain) at $15 \mathrm{~min}$ interval from completion of surgery and diclofenac sodium $75 \mathrm{mg}$ im was given when patients complained of VAS $>4$. Time for $1^{\text {st }}$ analgesic from completion of surgery ( $\mathrm{min}$ ) and total amount of analgesic required in $1^{\text {st }}$ $24 \mathrm{hrs}$ postoperatively were also recorded.

Postoperatively, all patients were given standard intravenous fluids (1L of Ringer's lactate solution and $1 \mathrm{~L}$ of $5 \%$ dextrose, for the next $24 \mathrm{~h}$ ). The patients were discharged 24 hours after the procedure after light meal, unless complications had occurred.

\section{Statistical Analysis}

All values were expressed as mean \pm standard deviation (SD). Sample size was estimated using the duration of the postoperative analgesia (Time required for $1^{\text {st }}$ Analgesic) as the main primary variable. As intra operative complications of group A totally differ from group $\mathrm{B}$ and $\mathrm{C}$ we have taken postoperative analgesia as main variable for estimation of sample size. On the basis of previous study, ${ }^{[10]}$ assuming a SD of 35 min for all groups and considering alpha risk 5\% and beta risk $15 \%$, it was estimated that 89 subjects in each group is required to evidence a difference averaging $30 \mathrm{~min}$ between the durations of post-operative analgesia. To increase the power of the study and to counter exclusion of cases due to conversion to GA or open cholecystectomy, we have included 100 subjects in each group.

Results were analysed by unpaired Student's t-test for parametric data and Mann-Whitney U-test for nonparametric data when two groups were compared. One-way ANOVA was used while comparing parametric data among the three groups. Chi-square test was used for comparing categorical data and proportions as appropriate. $\mathrm{P}<0.05$ was considered statistically significant. All statistical tests were done by "STATISTICA" version 9 (StatSoft, Inc. Tulsa, OK, USA).

\section{RESULTS}

From January 2014 to December 2016, 300 patients were enrolled in our study after meeting the inclusion criteria and were randomly divided into three groups. As four patients of group A were converted to open cholecystectomy sample size in this group was 96 . In group B two patients were converted to GA and two patients were converted to open cholecystectomy. One patient who was converted to GA was also converted to open cholecystectomy. Thus three patients were excluded from this group. In group $\mathrm{C}$ also three patients were excluded due to conversion to GA or open cholecystectomy. Thus, the sample size in group Band C was calculated to be 97 . (Figure 1)

No significant difference was observed regarding demography of the patient among the groups ( $p>0.05)$. Duration of surgery and pneumoperitoneum were also comparable among the different groups. (Table 1)

Incidence of hypotension, bradycardia and abdominal discomfort was significantly higher in group $\mathrm{C}$ compared to group B $(\mathrm{p}<0.05)$. Incidence of shoulder pain, hypertension, tachycardia and respiratory distress was comparable among group B and C ( $p>0.05)$. (Table 2)

No significant difference was observed in discharge time in any groups and all the patients were equally satisfied ( $p>0.05$ ). There was no significant difference in the surgeon satisfaction score among different groups ( $p>0.05)$.

Abdominal pain started significantly earlier in group A patients compared to other groups. When group $B$ and $C$ were compared abdominal pain started earlier in group B compared to group $\mathrm{C}(\mathrm{p}<0.05)$ though the amount of analgesic required is not significantly more $(p>0.05)$. Incidence of nausea vomiting was significantly more in patients who received GA compared to patients who received SA (both clonidine and fentanyl). Within first 6 hours of surgery hypotension and hypertension was significantly more in group $\mathrm{C}$ and group A respectively compared to other groups $(\mathrm{p}<0.05)$. Urinary retention and headache were complained by significant number of patients who received SA whereas sore throat was complained by $13.54 \%$ of the patients who received GA. 


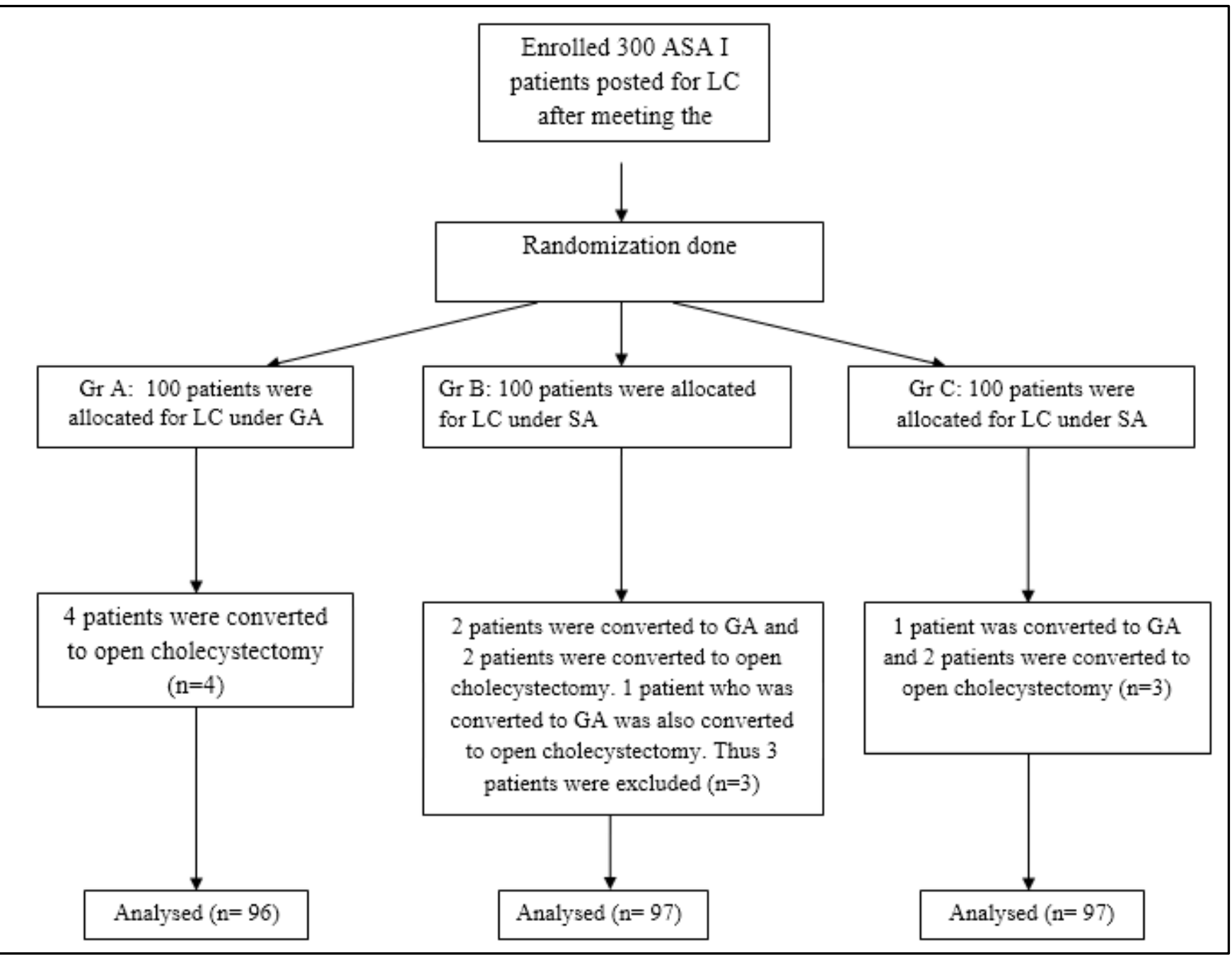

Figure 1

\begin{tabular}{|c|c|c|c|c|}
\hline & Gr A & Gr B & Gr C & P value \\
\hline Age & $42.41 \pm 5.38$ & $40.58 \pm 4.93$ & $43.29 \pm 5.62$ & $>0.05$ \\
\hline Sex (M/F) & $52 / 44$ & $49 / 48$ & $54 / 43$ & $>0.05$ \\
\hline Weight (Kg) & $56.39 \pm 6.71$ & $53.92 \pm 6.32$ & $57.63 \pm 7.11$ & $>0.05$ \\
\hline Height (cm) & $159.48 \pm 11.97$ & $159.82 \pm 13.63$ & $162.2 \pm 13.94$ & $>0.05$ \\
\hline Duration of Surgery (min) & $46.32 \pm 7.21$ & $41.73 \pm 6.92$ & $49.33 \pm 7.95$ & $>0.05$ \\
\hline Duration of Pneumoperitoneum (min) & $39.54 \pm 6.87$ & $35.52 \pm 6.75$ & $43.71 \pm 6.26$ & $>0.05$ \\
\hline \multicolumn{4}{|c|}{ Table 1 } \\
\hline
\end{tabular}

\begin{tabular}{|c|c|c|c|}
\hline & Group B (n=97) & Group C (n=97) & p value \\
\hline Shoulder Pain & $12(12.3 \%)$ & $10(10.3 \%)$ & $>0.05$ \\
\hline Hypotension & $62(63.91 \%)$ & $94(96.9 \%)$ & $<0.05$ \\
\hline Hypertension & $3(3.09 \%)$ & 0 & $>0.05$ \\
\hline Bradycardia & $12(12.37 \%)$ & $47(48.45 \%)$ & $<0.05$ \\
\hline Tachycardia & $15(15.46 \%)$ & $18(18.55 \%)$ & $>0.05$ \\
\hline Respiratory Distress & $9(9.27 \%)$ & $12(12.37 \%)$ & $>0.05$ \\
\hline Pain abdomen/ Abdominal Discomfort & $17(17.52 \%)$ & $39(40.2 \%)$ & $<0.05$ \\
\hline Pruritus (intra operative) & $1(0.01)$ & 0 & $>0.05$ \\
\hline Level of Sensory Block (median) & $\mathrm{T} 5$ & $\mathrm{~T} 4$ & $>0.05$ \\
\hline Intraoperative Fluid (ml) & $1387.3 \pm 147.9$ & $1538.1 \pm 178.3$ & $<0.05$ \\
\hline Intraoperative Ketamine (mg) & $29.24 \pm 5.71$ & $37.81 \pm 6.23$ & $<0.05$ \\
\hline Intraoperative Mephentermine (mg) & $9.83 \pm 2.91$ & $15.93 \pm 3.35$ & $<0.05$ \\
\hline Intraoperative Atropine (mg) & $0.11 \pm 0.014$ & $0.31 \pm 0.028$ & $<0.05$ \\
\hline \multicolumn{4}{|c|}{ Table 2. Intra Operative Events in Groups B and C } \\
\hline
\end{tabular}




\begin{tabular}{|c|c|c|c|c|c|c|}
\hline & \multirow{2}{*}{$\begin{array}{c}\text { Gr A } \\
(n=96)\end{array}$} & \multirow{2}{*}{$\begin{array}{c}\text { Gr B } \\
(n=97)\end{array}$} & \multirow{2}{*}{$\begin{array}{c}\text { Gr C } \\
(n=97)\end{array}$} & \multicolumn{3}{|c|}{ p-Value } \\
\hline & & & & (A-B) & (B-C) & (C-A) \\
\hline Discharge Time (hrs) & $25.23 \pm 2.71$ & $24.1 \pm 2.42$ & $25.89 \pm 2.94$ & $>0.05$ & $>0.05$ & $>0.05$ \\
\hline Patient Satisfaction Score & $4.29 \pm 0.23$ & $4.33 \pm 0.21$ & $4.21 \pm 0.26$ & $>0.05$ & $>0.05$ & $>0.05$ \\
\hline Surgeon Satisfaction Score & $4.21 \pm 0.19$ & $4.11 \pm 0.25$ & $4.15 \pm 0.25$ & $>0.05$ & $>0.05$ & $>0.05$ \\
\hline
\end{tabular}

\begin{tabular}{|c|c|c|c|c|c|c|}
\hline & $\begin{array}{c}\text { Gr A } \\
(n=96)\end{array}$ & $\begin{array}{c}\text { Gr B } \\
(n=97)\end{array}$ & $\begin{array}{c}\text { Gr C } \\
(n=97)\end{array}$ & $\begin{array}{l}\text { P value } \\
\text { (A-B) }\end{array}$ & $\begin{array}{l}\text { P value } \\
\text { (B-C) }\end{array}$ & $\begin{array}{l}\text { P value } \\
\text { (C-A) }\end{array}$ \\
\hline Pain Abdomen (within 2 hrs of surgery) & $94(97.91 \%)$ & $35(36.08 \%)$ & $12(12.37 \%)$ & $<0.05$ & $<0.05$ & $<0.05$ \\
\hline Nausea/Vomiting & $28(29.16 \%)$ & $15(15.46 \%)$ & $12(12.37 \%)$ & $<0.05$ & $>0.05$ & $<0.05$ \\
\hline Urinary Retention & $2(2.08 \%)$ & $24(24.74 \%)$ & $29(29.89 \%)$ & $<0.05$ & $>0.05$ & $<0.05$ \\
\hline Hypotension (within 6 hrs of surgery) & 0 & $3(3.09 \%)$ & $25(25.77 \%)$ & $>0.05$ & $<0.05$ & $<0.05$ \\
\hline Headache & 0 & $10(10.3 \%)$ & $8(8.24 \%)$ & $<0.05$ & $>0.05$ & $<0.05$ \\
\hline Sore Throat & $13(13.54 \%)$ & 0 & 0 & $<0.05$ & $>0.05$ & $<0.05$ \\
\hline Pruritus (Post-operative) & 0 & 0 & 0 & $>0.05$ & $>0.05$ & $>0.05$ \\
\hline Post-Operative Surgical Complications & $4(0.04 \%)$ & $3(0.03 \%)$ & $4(0.04 \%)$ & $>0.05$ & $>0.05$ & $>0.05$ \\
\hline Hypertension (within 6 hrs of surgery) & $21(21.87 \%)$ & $2(2.06 \%)$ & $3(3.09 \%)$ & $<0.05$ & $>0.05$ & $<0.05$ \\
\hline $\begin{array}{c}\text { Time for } 1^{\text {st }} \text { Analgesic from Completion of } \\
\text { Surgery (min) }\end{array}$ & $\begin{array}{c}20.34 \pm \\
5.23 \\
\end{array}$ & $\begin{array}{c}184.49 \pm \\
23.71 \\
\end{array}$ & $\begin{array}{l}225.17 \pm \\
28.92 \\
\end{array}$ & $<0.05$ & $<0.05$ & $<0.05$ \\
\hline $\begin{array}{l}\text { Total Amount of Analgesic Required in 1st } \\
24 \text { hrs. Postoperative (mg) Period }\end{array}$ & $\begin{array}{c}124.62 \pm \\
13.9 \\
\end{array}$ & \begin{tabular}{|c|}
$97.72 \pm$ \\
10.48 \\
\end{tabular} & $\begin{array}{c}91.43 \pm \\
9.11 \\
\end{array}$ & $<0.05$ & $>0.05$ & $<0.05$ \\
\hline \multicolumn{7}{|c|}{ Table 4. Postoperative Events } \\
\hline
\end{tabular}

\section{DISCUSSION}

Pneumoperitoneum produces systemic effects due to the absorption of $\mathrm{CO}_{2}$ and decreased venous return due to the increased intra-abdominal pressure.[10] Carboxemia produced by absorption of $\mathrm{CO}_{2}$ induces respiratory acidosis decreasing arterial and mixed venous $\mathrm{pH}$ and $\mathrm{PaO}_{2 .}{ }^{[11]}$ Due to these adverse effects of $\mathrm{CO}_{2}$ pneumoperitoneum, previously controlled ventilation under GA was preferred. But in recent years several studies and case series have establish the safety and feasibility of spinal anaesthesia for LC particularly in healthy patients who have no serious cardiopulmonary disease to eliminate the $\mathrm{CO}_{2}$ by spontaneous ventilation. ${ }^{[3,4,12]}$ In the present study, the study population was also restricted to ASA I patients to eliminate patients with serious cardio respiratory problems.

Clonidine, a selective partial $\alpha_{2}$ agonist prolongs the duration of both sensory and motor block of local anaesthetic after intrathecal administration and exerts its analgesic effects via post synaptic $\alpha 2$ receptors in substantia gelatinosa of spinal cord.[13,14] Various doses of clonidine have been used intrathecally with varying doses of bupivacaine.[15,16,17] Increasing the of dose of intrathecal clonidine also increases the side effects like sedation, hypotension, bradycardia and prolongation of blockade.[17] In two studies very small doses of intrathecal clonidine $(25 \mu \mathrm{g}$ and $30-75 \mu \mathrm{g}$ ) has adequate prolongation of blockade without much side effects.[18,19] In our study we have chosen a smaller dose of clonidine (30 mcg) to minimize side effect.

Fentanyl when administered with local anaesthetic has a synergistic inhibitory action on the A $\delta$ and C- fiber conduction resulting improved perioperative analgesia.[20] Significant prolongation of the postoperative analgesia was observed when fentanyl was administered in 0.5 and 0.75 $\mu \mathrm{g} / \mathrm{kg}$. ${ }^{21]}$ Pruritus, a unique feature of intrathecal opioids and it is increased with incremental doses of fentanyl. Previous studies demonstrated that fentanyl $25 \mu \mathrm{g}$ reduced the analgesic requirement without increasing the incidence of episodes of desaturation, nausea, or pruritus during the early postoperative period.[21,22] So, we decided to go with a dose of
$25 \mu \mathrm{g}$ to minimize the side effects as well as to increase the postoperative analgesia.

Intra operative abdominal discomfort is one of the main disadvantages of spinal anaesthesia for laparoscopic cholecystectomy. In the present study, patients of group B experienced significantly less abdominal discomfort compared to group C. Significant reduction of visceral and somatic pain improving quality of block by intrathecal fentanyl may be the possible explanation of less abdominal discomfort and lesser use of intra operative ketamine in group B.[22,23]

In the present study incidence of hypotension was significantly more in group C compared to other groups. Our observation is similar to previous studies where fentanyl and clonidine were used intrathecally with bupivacaine. $[9,15,17,24]$ Higher block height required for LC may also be responsible for higher incidence of hypotension and bradycardia in group $\mathrm{C}$ even with smaller dose of clonidine.

Incidence of shoulder pain while doing LC under regional anaesthesia, has been reported as ranging from $25 \%$ $43 \% \cdot[2,4,12,25]$ This was probably due to high intra-abdominal pressure (IAB) used in these studies. In our study referred right shoulder pain in group $\mathrm{B}$ and $\mathrm{C}$ were $12.3 \%$ and $10.3 \%$ which is statistically not significant. The lower incidence of shoulder pain our study compared to previous studies is probably due to low IAP ( $<10 \mathrm{mmHg}$ ) and liberal use of local anaesthetic to bath under surface of diaphragm. Our observation regarding shoulder pain is similar to the study where both local anaesthetic and low IAP were used.[3]

In all the cases done under spinal anaesthesia no technical problem was faced by the surgeons similar to previous studies. As obese patient may need to increase IAP more than $10 \mathrm{mmHg}$ we have excluded patients with $\mathrm{BMI}>30$.

Duration of post-operative analgesia and time for requirement of $1^{\text {st }}$ analgesic was significantly increased in group C compared to group B. Our observation with intrathecal clonidine regarding post-operative analgesia is similar to previous studies when compared to fentanyl.[9,15,24] 
We have excluded obese patient and included only ASAI patients which are limitations of the present study. Further study with ASA I and II patients and carefully selected patients with higher body mass indexes may be done in future to overcome this limitation.

\section{CONCLUSION}

Intrathecal fentanyl as adjuvant to bupivacaine is a preferred choice as it significantly reduces intra operative abdominal discomfort. Though duration of post-operative analgesia is more with clonidine compared to fentanyl, higher incidence of hypotension and bradycardia with clonidine outweighs this advantage.

\section{REFERENCES}

[1] Sharp JR, Pierson WP, Brady CE 3rd. Comparison of CO2 and N2O-induced discomfort during peritoneoscopy under local anaesthesia. Gastroenterology 1982;82(3):453-6.

[2] Gautam B. Spinal anaesthesia for laparoscopic cholecystectomy: a feasibility and safety study. Kathmandu Univ Med J (KUMJ) 2009;7(28):360-8.

[3] Tiwari S, Chauhan A, Chaterjee P, et al. Laparoscopic cholecystectomy under spinal anaesthesia: a prospective, randomised study. Journal of Minimal Access Surgery 2013;9(2):65-71.

[4] Sinha R, Gurwara AK, Gupta SC. Laparoscopic cholecystectomy under spinal anaesthesia: a study of 3492 patients. J Laparoendosc Adv Surg Tech A 2009;19(3):323-7.

[5] Ellakany M. Comparative study between general and thoracic spinal anesthesia for laparoscopic cholecystectomy. Egyptian Journal of Anaesthesia 2013;29:375-81.

[6] Hajong R, Khariong PDS, Baruah AJ, et al. Laparoscopic cholecystectomy under epidural anesthesia: a feasibility study. N Am J Med Sci 2014;6(11):566-9.

[7] Loubert C. Fluid and vasopressor management for cesarean delivery under spinal anesthesia: continuing professional development. Can J Anaesth 2012;59(6):604-19.

[8] Bhar D, RoyBasunia S, Das A, et al. A comparison between intrathecal clonidine and neostigmine as an adjuvant to bupivacaine in the subarachnoid block for elective abdominal hysterectomy operations: a prospective, double-blind and randomized controlled study. Saudi Journal Anaesthesia 2016;10(2):121-6.

[9] Bhattacharjee A, Singh NR, Singh SS, et al. A comparative study of intrathecal clonidine and fentanyl along with bupivacaine in spinal anesthesia for caesarean section. Journal of Medical Society 2015;29(3):145-9.

[10] Kotzampassi K, Kapanidis N, Kazamias P, et al. Hemodynamic events in the peritoneal environment during pneumoperitoneum in dogs. Surg Endosc 1993;7(6):494-9.
[11] Gandara V, de Vega DS, Escriu N, et al. Acid-base balance alterations in laparoscopic cholecystectomy. Surg Endosc 1997;11(7):707-10.

[12] Tzovaras G, Fafoulakis F, Pratsas K, et al. Laparoscopic cholecystectomy under spinal anaesthesia: a pilot study. Surg Endosc 2006;20(4):580-2.

[13] Chiari A, Eisenach JC. Spinal anaesthesia: mechanisms, agents, methods and safety. Reg Anesth Pain Med 1998;23(4):357-62: discussion 384-7.

[14] Reddy SV, Yaksh TL. Spinal noradrenergic terminal system mediates antinociception. Brain Res 1980;189(2):391-401.

[15] Benhamou D, Thorin D, Brichant JF, et al. Intrathecal clonidine and fentanyl with hyperbaric bupivacaine improves analgesia during cesarean section. Anesth Analg 1998;87(3):609-13.

[16] Paech MJ, Pavy TJ, Orlikowski CE, et al. Postcesarean analgesia with spinal morphine, clonidine or their combination. Anesth Analg 2004;98(5):1460-6.

[17] Filos KS, Goudas LC, Patroni O, et al. Intrathecal clonidine as a sole analgesic for pain relief after caesarean section. Anesthesiology 1992;77(2):267-74.

[18] Pederson H, Santos AC, Steinberg ES, et al. Incidence of visceral pain during cesarean section: the effect of varying doses of spinal bupivacaine. Anesth Analg 1989;69(1):46-9.

[19] Alahuhta S, Kangas-Saarela T, Hollmén AI, et al. Visceral pain during caesarean section under spinal and epidural anaesthesia with bupivacaine. Acta Anaesthesiol Scand 1990;34(2):95-8.

[20] Wang C, Chakrabarti Mk, Whitwam JG. Specific enhancement by fentanyl of the effects of intrathecal bupivacaine on nociceptive afferent but not on sympathetic efferent pathways in dogs. Anaesthesiology 1993;79(4):766-73: discussion 25A.

[21] Belzarena SD. Clinical effects of intrathecally administered fentanyl in patients undergoing cesarean section. Anesth Analg 1992;74(5):653-7.

[22] Singh H, Yang J, Thornton K, et al. Intrathecal fentanyl prolongs bupivacaine sensory block. Can J Anaesth 1995;42(11):987-91.

[23] Gutstein HB, Akil H. Opioid analgesics. In: Gilman AG, Hardman JG, Limbird LE, eds. Goodman and Gilman's the Pharmacological Basis of Therapeutics. 10th edn. USA: McGraw-Hill 2001: p. 595-6.

[24] Thakur A, Bhardwaj M, Kaur K, et al. Intrathecal clonidine as an adjuvant to hyperbaric bupivacaine in patients undergoing inguinal herniorrhaphy: a randomized double-blinded study. Journal of Anaesthesiology Clinical Pharmacology 2013;29(1):66-70.

[25] Ali Y, Elmasry MN, Negmi H, et al. The feasibility of spinal anesthesia with sedation for laparoscopic general abdominal procedures in moderate risk patients. Middle East J Anesthesiol 2008;19(5):102739. 